Cristianne Maria Famer Rocha ${ }^{1}$

Letícia Lassen Petersen ${ }^{1}$ Lígia Daiane Fink dos Santos ${ }^{2}$

\title{
O PÚBLICO E 0 PRIVADO, AS PATENTES E A SAÚDE: ESTUDO DA FRAUDE DE FARMACÊUTICAS NA ITÁLIA COMPARADO À LEGISLAÇÃO BRASILEIRA
}

The public and the private, the patents and health: study of pharmaceutical companies fraud in Italy compared to the Brazilian legislation

${ }^{1}$ Universidade Federal do Rio Grande do Sul. Porto Alegre/RS, Brasil.

${ }^{2}$ Faculdade de Educação e Tecnologia da Região Missioneira. São Paulo das Missões/RS, Brasil.

Correspondência: Letícia Lassen Petersen. E-mail: letipetersen@yahoo.com.br.

Recebido em: 13/12/2016. Revisado: 02/05/2017. Aprovado: 11/05/2017. 


\section{RESUMO}

O presente artigo aborda os obstáculos à regulação econômica do comércio de medicamentos no Brasil. A delimitação temática recai sobre o caso italiano de prática de conluio por parte de duas empresas do ramo farmacêutico para fraudar o sistema de saúde e a existência de indícios da mesma prática no Brasil. A prática do crime contra a ordem econômica e financeira respingou na própria organização do sistema público de saúde italiano e as empresas foram consideradas culpadas pela prática criminosa. O caso retoma a discussão da necessidade de intervenção estatal na economia - do ponto de vista tanto da regulação do mercado quanto da fiscalização do que é efetivamente ofertado à população pelo comércio -, com vistas à promoção da dignidade da pessoa humana, o que inclui a proteção da saúde pelo Estado. A pesquisa tem por objetivo sistematizar o caso italiano de duplicidade no registro de patente, paralelamente abordando a regulação econômica do registro dos medicamentos no Brasil e a criminalização do conluio nessa seara, para, então, testar a hipótese de pesquisa de que a mesma conduta empresarial de duplo registro da patente também foi adotada no Brasil. O método hipotético dedutivo conduz a realização da pesquisa, oferecendo ao leitor a sistematização do caso escolhido e conceitos com base em pesquisa bibliográfica e documental (livros, jornais de repercussão internacional, revistas científicas, artigos científicos, bulas dos medicamentos envolvidos e legislação brasileira sobre a matéria) para, assim, dialogar acerca dos fatos.

\section{Palavras-Chave}

Comércio de Medicamentos; Direito Italiano; Indústria Farmacêutica; Legislação Brasileira; Patente.

\section{ABSTRACT}

This article discusses the obstacles to economic regulation of medicines trade in Brazil. The theme focuses on the case of two Italian companies of the pharmaceutical industry which got involved in the practice of collusion in order to fraud the health system, and the existence of evidences of this practice in Brazil. The practice of this crime against the economic and financial order affected the very organization of the Italian public health system, and the companies were considered guilty of illegal practice. This case resumes the discussion about the need of state intervention in the economy: both from the point of view of trade regulations and the monitoring of what the drug retailers actually offer to the population, with the aim of fostering human dignity, which includes the State's protection to health. This research aims at systematizing the duplicity of patent registration in the Italian case, approaching in parallel the economic regulations in Brazil regarding drugs, as well as criminalization of collusion in this area, and then test the research hypothesis that the same business behavior has also been practiced in Brazil. This research is guided by the hypothetical-deductive method, providing the reader with a systematization of the case at issue and concepts through bibliographic and documental research (books, international newspapers, scientific magazines, scientific articles, the involved drugs description leaflets and Brazilian legislation about the subject) to finally discuss the facts.

\section{Keywords}

Brazilian Legislation; Italian Law; Medicines Trade; Patent; Pharmaceutical Industry. 


\section{Introdução}

O princípio constitucional da dignidade do ser humano está relacionado com a qualidade de vida das pessoas e seu bem-estar, em que se inclui o direito à saúde, previsto entre as políticas sociais do Estado brasileiro. Nesse sentido, o acesso da população a medicamentos - independentemente do fator de compra particular ou do alcance público - faz parte das estratégias para a promoção e efetivação do direito à saúde.

Internacionalmente se discute $o$ acesso a medicamentos enquanto um indicador de qualidade dos serviços públicos no setor. Conforme o Parlamento Europeu, por refletir a preocupação dos Estados com a vida da população:

$\mathrm{O}$ acesso a medicamentos é reconhecido internacionalmente como um importante indicador de qualidade da prestação de serviços em saúde. $\mathrm{O}$ acesso a medicamentos, definido como a possibilidade de o paciente obter medicamentos, refere-se a se e como as pessoas estão obtendo seus medicamentos, incluindo como os utilizam, o quanto pagam por eles e qual é a carga desse gasto na renda pessoal total ${ }^{1}$. (Tradução livre.)

O medicamento merece um olhar diferenciado pelo setor público, pois, diferentemente de um bem de consumo, não é objeto das escolhas consumeristas dos cidadãos, pois se trata de um bem necessário à saúde e a uma melhor qualidade de vida do sujeito. Assim, esta pesquisa volta-se para a sistematização da regulação econômica dos medicamentos no Brasil, necessários para a preservação da vida; ao mesmo tempo, visa a demonstrar os interesses privados que circundam esse setor quando $o$ assunto é exploração exclusiva e estratégias adotadas para prorrogação de patentes.

O objetivo desta pesquisa é dar publicidade ao caso de duplo registro da patente de um mesmo sal, sob a denominação de dois distintos medicamentos, aparentemente descobertos por empresas diferentes, ocorrido na Itália - país que privilegia a proteção de marcas e patentes - e investigar como se encontra a situação desses fármacos no Brasil. Nesse trajeto, a abordagem de como o Estado Democrático de Direito brasileiro repele a prática de cartel/conluio no país ganha espaço, a fim de perquirir a real proteção dos sujeitos frente aos interesses de obtenção de lucro do capital nesse mercado tão sensível, que é a saúde do cidadão. $\mathrm{O}$ caso italiano desvela a ação em conluio de duas gigantes empresas farmacêuticas que, valendo-se

\footnotetext{
${ }^{1}$ No original: "Access to medicines is recognised internationally as an important quality indicator of health service provision. Access to medicines, defined as the patient's possibility to obtain medicines, concerns if and how people are obtaining their medicines, including how they use them, how much they pay for them and what is the burden of this payment on the overall personal income." EUROPEAN PARLIAMENT. Links between pharmaceutical $\mathrm{R} \& D$ models and access to affordable medicines. Directorate General for Internal Policies Policy Department a: Economic and Scientific Policy, 2016. p. 119. Disponivel em: <http://www.europarl.europa.eu/RegData/etudes/ STUD/2016/587321/IPOL_STU(2016)587321_EN.pdf>. Acesso em: 29 mar. 2017.
} 
da proteção à propriedade intelectual pelo Estado da Itália, depositaram em duplicidade a mesma patente de invento, sob denominação diferente e para o tratamento de quadros diagnósticos distintos. A ação causou sério impacto no sistema público de saúde italiano. A investigação culminou na condenação das empresas ao ressarcimento dos valores gastos desnecessariamente pelo sistema público de saúde, além do pagamento de multas pecuniárias com vistas a puni-las pela adoção dessa prática desleal. Com esta pesquisa, busca-se comprovar a necessidade de regulação estatal no setor farmacêutico a fim de garantir o acesso da população aos fármacos e a segurança dos medicamentos, além da justiça no acesso da população aos tratamentos, fundamentada na promoção da dignidade da pessoa humana e na proteção da saúde pelo Estado.

Para atender os objetivos propostos, a metodologia adotada é teórico-empírica. Teórica porque se dedica a um estudo de normas, doutrinas e informações, buscando fontes bibliográficas e oferecendo material compilado acerca da complexa regulamentação do mercado de medicamentos no Brasil. Já em sua face empírica, a pesquisa realiza estudo comparado do fato criminoso contra a ordem econômica na Itália à luz da legislação brasileira, facilitando a aproximação prática do conhecimento com a realidade de forma comparada.

O leitor encontrará uma descrição da situação de conluio ocorrida na Itália em que empresas farmacêuticas fraudaram tanto os consumidores quanto o sistema público de saúde italiano -, acompanhada de um breve panorama sobre a proteção da propriedade intelectual. Após a descrição do caso italiano, faz-se a análise do registro, no Brasil, dos medicamentos envolvidos na fraude daquele país. Discute-se, com base na legislação pátria, as consequências dessa prática para as empresas, uma vez que o Estado visa à proteção da saúde física e financeira do consumidor e do sistema público de saúde.

O tema é de grande relevância social, pois aborda a responsabilidade do Estado em relação à regulação do setor farmacêutico, a viabilização de exploração de monopólios oriundos de patentes e a proteção do mercado nacional e do próprio Estado (que oferece tratamentos em suas políticas sociais) frente aos interesses econômicos que circundam todas as decisões públicas, especialmente em tempos nos quais a indústria farmacêutica desponta e deseja se manter como uma das mais lucrativas do planeta. Nota-se que a regulamentação é imprescindível, pois tanto o consumidor como o Estado estão vulneráveis aos interesses que visam a potencializar lucros, seja por meio do estímulo ao uso irracional de fármacos (o que inclui a automedicação), seja por meio do estímulo à busca de tratamentos inovadores - na vigência de patentes - nem sempre considerados seguros e eficazes pela literatura médica.

A partir da pesquisa realizada, foi possível refletir sobre a necessidade de o Estado manter a regulação do setor farmacêutico como fortaleza, adotando estratégias multidisciplinares que envolvam os diversos órgãos e setores do poder público 
a fim de controlar o registro de patentes ${ }^{2}$, preço, qualidade, efetividade, segurança e eficácia. Parte-se do pressuposto de que o medicamento é um bem público em toda a sua extensão ${ }^{3}$ e que a saúde é um direito fundamental que deve ser efetivado para todas as pessoas - mesmo para aqueles que optam pelo financiamento particular de suas necessidades terapêuticas. Pondera-se a necessidade de que ainda mais criteriosa deve se revestir a regulação que envolve a inserção de medicamentos na Relação Nacional de Medicamentos Essenciais (Rename) do Sistema Único de Saúde (SUS), pois este inquestionavelmente tem um compromisso com a inesgotabilidade do acesso de todos os cidadãos brasileiros ao bem público.

\section{Conluio entre empresas farmacêuticas em nome da potencialização dos lucros}

Pensar na efetivação da dignidade humana pelo Estado pressupõe a preservação do bem mais valioso dos cidadãos, expresso em sua própria existência. A qualidade de vida individual está diretamente relacionada à saúde das pessoas e ao direito à preservação da saúde, oportunizada pelo Estado. A proteção à vida constitui o verdadeiro desafio do Estado contemporâneo, uma vez que os interesses econômicos nem sempre se comprometem a fazê-lo por se voltarem a uma lógica de acumulação de riquezas, que não coaduna com a proteção da existência. É por esse fundamento que a necessidade de regulação estatal é imperativa em setores relacionados à saúde (que começa no âmbito alimentar e perpassa por produtos de uso pessoal, drogas/medicamentos, contratos de consumo, entre outros), ao meio ambiente, às relações de trabalho, à seguridade social etc.

O caso que chocou a Itália e chama atenção em todos os países revela a fragilidade dos cidadãos frente os interesses econômicos e apresenta a voracidade com que o capitalismo age na potencialização de sua lucratividade. A forma de se construírem barreiras para essas ações, que atingem os sujeitos, perpassa pela organização de políticas sociais que condicionam o capital à promoção dos interesses do bem comum, o que exige a consolidação de um Estado Democrático forte, amparado em políticas sociais claras e comprometidas com a população.

Os espaços geográficos sobre os quais recai a pesquisa - Brasil e Itália -, ao organizarem sua atuação, adotam o planejamento de políticas sociais para justamente programar ações capazes de corrigir as distorções do sistema capitalista.

\footnotetext{
${ }^{2} \mathrm{O}$ Instituto Nacional de Propriedade Industrial (INPI) é responsável pelo depósito de patentes. No caso de medicamentos, a Agência Nacional de Vigilância Sanitária (Anvisa) é chamada a se manifestar, além de acompanhar o processo de descrição técnica e avaliação da segurança e eficácia para indicação em bula pretendida pela indústria farmacêutica.

${ }^{3}$ PETERSEN, Letícia Lassen. Políticas sociais no SUS e a gestão da assistência farmacêutica na rede local/ regional: o caso da judicialização na $17^{\text {a }}$ Coordenadoria Regional de Saúde - RS. 2014. Tese (Doutorado em Direito), Faculdade de Direito, Universidade de Santa Cruz do Sul, 2014. Disponível em: <http://btd.unisc. br/Teses/LeticiaPetersen.pdf>. Acesso em: 29 mar. 2017.
} 
Merece destaque o fato de os textos constitucionais dos dois países, ao abordarem a concepção de cidadania, terem acolhido a regulação econômica e a oferta de políticas sociais por parte do Estado como forma de proteção dos cidadãos. É ponto comum o jogo de equilíbrio entre a proteção de interesses do capital - a exemplo da propriedade intelectual, que premia o inventor com a exploração de uma patente econômica, criando meios para tal - e a oferta de políticas sociais aos cidadãos - a exemplo do direito à saúde.

O direito à saúde é regulado nesses países no contexto de uma política de acesso universal e inclui prestações de serviços de saúde, bem como a disponibilidade de um elenco de medicamentos pelo Estado sob a forma de bem público, em nome da proteção a vida, destinados à prevenção e cura de eventos classificados como doença. Os medicamentos têm um papel significativo na melhoria da qualidade de vida das pessoas, evidentemente constituindo-se em um elemento fundamental à proteção e à manutenção da saúde dos indivíduos. Porém, há que se atentar para o fato de que o "bem medicamento" guarda peculiaridades distintas de um bem de consumo trivial, uma vez que não se encontra entre aqueles bens de consumo alternativos à vida ou relacionados ao prazer dos sujeitos; o medicamento, em caso de doença, faz parte das necessidades vitais. Ao ser alocado na categoria de bem público, o medicamento está revestido dos adjetivos de necessidade e imprescindibilidade, qualidades que se sobrepõem aos interesses da indústria farmacêutica no lucro.

Em razão dessa característica peculiar - a da necessidade básica -, o medicamento não pode ser comparado ou regulado como um bem de consumo que se reveste de liberalidade para possuí-lo. Ele deve ser considerado um bem público em toda a sua extensão, o que não direciona a ação de Estado apenas aos casos de fornecimento direto e gratuito de medicamentos por meio da construção de uma política nacional de assistência farmacêutica, e sim torna ainda mais imprescindíveis a regulação e fiscalização dos produtos postos para comercialização nas prateleiras de farmácias particulares ${ }^{4}$.

A discussão e a regulação do medicamento enquanto bem público é essencial para a preservação da saúde humana, desde seu ingresso no território nacional até sua oferta. A regulação é uma forma de ação preventiva do Estado em relação ao acesso da população às substâncias que impactam a saúde ${ }^{5}$.

Os interesses que circundam esse bem devem ser atentamente acompanhados pelo Estado, pois a mesma substância que guarda a capacidade da cura também é capaz de expor a risco, quando seu uso pelos sujeitos for indiscriminado ou irracional. Pode-se destacar como essencial o acompanhamento do registro da

${ }^{4}$ PETERSEN, Letícia Lassen. op. cit.

${ }^{5}$ Id. Ibid. 
patente, da produção da substância e do acesso da população a ela (o que envolve desde a negociação pública do preço até a exigência de uma prescrição médica).

O setor privado - e a lógica capitalista que o reveste - percebe o medicamento como produto, como uma forma de obtenção de lucro. Embora muitos produtos da área farmacêutica sejam produzidos em indústrias públicas, aqueles que estão na vigência de patentes constituem-se em monopólio de determinada empresa farmacêutica, normalmente privada. Essas empresas submetem-se a uma lógica de lucratividade, pautada pela "meritocracia da descoberta" presente no discurso da Organização Mundial do Comércio (OMC) e que garante a exploração econômica de inventos por determinado período como uma recompensa ao pesquisador que dedicou tempo e recursos e empenhou esforços para tal. Nem todos os produtos fornecidos nos sistemas públicos de saúde são produzidos pelo Estado e/ou tiveram sua patente expirada ${ }^{6}$.

O caso abordado nesta pesquisa enfrenta justamente a vulnerabilidade dos cidadãos frente à viabilidade de proteção ao monopólio de exploração comercial, gerado pelo depósito da patente em nome da proteção à propriedade intelectual, especialmente na área farmacêutica. O interesse na monopolização da produção é demonstrado pela busca desmedida pelo lucro na comercialização, especialmente nesse setor, que não mede esforços para manter a exploração da patente.

A fraude descoberta pelo Ministério da Saúde da Itália repercutiu mundialmente, questionando duas empresas quanto ao registro e ao depósito dos medicamentos envolvidos: as companhias farmacêuticas Novartis e Roche. Elas foram consideradas culpadas de formação de cartel por terem dificultado a comercialização de um remédio mais econômico (Avastin ${ }^{\circledR}$ ) em favor de outro muito mais caro (Lucentis ${ }^{\circledast}$ ), embora ambos tivessem princípio ativo análogo (idêntico sal) e fórmulas semelhantes, que poderiam ser destinadas para o mesmo fim.

As duas potências da indústria farmacêutica resolveram, em conjunto, desestimular a venda de um medicamento com preço mais acessível, indicado para tratamento de degeneração macular relacionada à idade (DMRI), o Avastin ${ }^{\oplus}$, inicialmente aprovado para o tratamento oncológico. A oferta do Avastin ${ }^{\circledast}$ foi reduzida, direcionando a venda e a procura pelo Lucentis ${ }^{\circledast}$, medicamento que atua da mesma forma, contudo com preço muito elevado justificado pelo depósito de nova patente. Enquanto o Lucentis ${ }^{\oplus}$ estava sendo comercializado pelo custo de $€ 900$ (novecentos euros) por aplicação, o Avastin ${ }^{\circledast}$ era comercializado por $€ 30$ a cada aplicação.

Como país-membro da OMC, a Itália - assim como o Brasil - reconhece os direitos de propriedade intelectual àqueles que depositam a patente do invento. Porém, no setor farmacêutico, deveria ser considerada a possibilidade de

${ }^{6}$ PETERSEN, Letícia Lassen. op. cit. 
flexibilização dos direitos de exploração menos extraordinária das patentes, no caso do interesse de sua exploração frente à proteção da saúde da população. Autores italianos já se posicionaram nesse sentido, a exemplo de Pammolli e Salerno: “[...] existem circunstâncias que ensejam uma relativização do direito de propriedade, para garantir interesses coletivos ou por motivos de urgência"” (tradução livre).

A situação descoberta na Itália - que escancarou a prática de conluio das empresas, que registraram em duplicidade o mesmo sal para doenças diferentes com o objetivo de estender a patente - coloca a necessidade de revisão da forma como os Estados que são países-membros da OMC e que ratificaram o Acordo sobre Aspectos dos Direitos de Propriedade Intelectual Relacionados ao Comércio ${ }^{8}$ (TRIPS, na sigla em inglês) têm conduzido o depósito de patentes de medicamentos. Segundo notícia veiculada na página da Deco Proteste (associação portuguesa sem fins lucrativos para defesa dos direitos do consumidor), só em 2012 a prática de conluio das empresas custou ao Estado italiano mais de 42 milhões de euros e teme-se que os custos acrescidos no futuro venham a superar os 600 milhões de euros anuais. $O$ ato é ainda mais condenável tendo em conta que, com a atual crise econômica, muitos países europeus lutam com dificuldades para pagar medicamentos e garantir à população o acesso a tratamentos. Na verdade, a estratégia das duas farmacêuticas fez com que algumas pessoas ficassem sem tratamento em razão do custo associado a ele'.

A agência nacional italiana de notícias veiculou a informação de que o Ministério da Saúde da Itália, chefiado por Beatriz Lorenzin, publicizou a formação de cartel pelas empresas Novartis e Roche e adotou medidas para ressarcir os prejuízos financeiros vivenciados pelo país, nos seguintes termos:

O Ministério da Saúde da Itália pediu um ressarcimento de $€ 1,2$ bilhão ( $\$$ \$ 3,6 bilhões) às companhias farmacêuticas Novartis e Roche por elas terem formado um cartel para dificultar a comercialização de um remédio econômico em favor de outro muito mais caro, embora ambos sejam semelhantes. O caso começou em 2004, quando pesquisadores da Genetech, subsidiária da Roche, desenvolveram um medicamento antitumoral bevacizumab, que foi colocado no mercado sob o nome de Avastin. No entanto, descobriu-se que ele também poderia ser útil para

${ }^{7}$ No original: “[...] esisto no delle circostanze in cuiil diritto di proprietà può esse rea ffievolito, a garanzia di interessi collettivi o per motivi di urgenza [...]". PAMMOLLI, F; SALERNO, N. C. Distribuzione dei farmaci, tutela della salute e diritti soggettivi. Roma: CERM, 2006.

8INSTITUTO NACIONAL DE PROPRIEDADE INTELECTUAL. Decreto n. 1.355, de 30 de dezembro de 1994. Promulgo a Ata Final que Incorpora os Resultados da Rodada Uruguai de Negociações Comerciais Multilaterais do GATT. Disponivel em: <http://www.inpi.gov.br/legislacao-1/27-trips-portugues1.pdf>. Acesso em: 31 out. 2017.

${ }^{9}$ Novartis e Roche multadas em Itália por concorrência desleal. Associação sem fins lucrativos para a defesa do consumidor, maio 2014. Disponível em: <http://www.deco.proteste.pt/saude/medicamentos/noticia/ novartis-e-roche-multadas-em-italia-por-concorrencia-desleal\#>. Acesso em: 25 out. 2015. 
curar uma série de doenças que atingem a vista, principalmente de idosos, como a maculopatia e retinopatias diabéticas. Pouco depois, a empresa se baseou nessa fórmula para criar o remédio ranibizumab, chamado comercialmente de Lucentis e dedicado exclusivamente a patologias oculares. Os dois são basicamente iguais, com exceção do preço: uma injeção desse último pode custar mais de US\$ 2 mil (R $\$ 4,5$ mil), enquanto a do Avastin sai por cerca de US\$ 40 (R\$90). Esse remédio mais caro é vendido nos Estados Unidos pela Genentech, enquanto no resto do mundo está sob licença da Novartis. Segundo o órgão antitruste italiano, as duas companhias entraram em acordo para desencorajar o uso do fármaco mais barato no combate a doença nos olhos, incentivando a utilização do Lucentis [...] "Houve um acordo horizontal com o objeto de beneficiar a comercialização do Lucentis, muito mais caro que os Avastin, mesmo eles sendo equivalentes", diz um comunicado do Ministério da Saúde da Itália. O valor da multa refere-se aos prejuízos causados ao sistema sanitário do país desde $2012^{10}$.

Em razão das investigações realizadas pelas autoridades italianas antimonopólio, as empresas suíças Novartis e Roche foram condenadas a uma multa bilionária, com o intuito de punir e ressarcir os prejuízos causados ao governo italiano desde 2012, quando o medicamento passou a ser utilizado pelo sistema de saúde italiano como única alternativa segura para o tratamento da DMRI.

Como o medicamento ranibizumabe (Lucentis ${ }^{\circledR}$ ) é uma das alternativas comprovadamente eficazes no tratamento da DMRI e tem sido utilizado em saúde pública, causando prejuízos ao sistema de saúde dos Estados, uma vez que existe outro medicamento cuja patente já expirou e que poderia ser igualmente utilizado para o tratamento da DMRI - o medicamento bevacizumab (Avastin ${ }^{\circledast}$ ).

No Brasil, a situação de depósito das patentes é idêntica à italiana. O fármaco Avastin $^{\oplus}$ possui registro junto à Agência Nacional de Vigilância Sanitária (Anvisa), com aprovação de sua bula para o tratamento oncológico em maio de $2013^{11}$, e o fármaco Lucentis ${ }^{\oplus}$, para degeneração macular relacionada à idade, teve sua bula aprovada pela Anvisa em abril de $2013^{12}$.

A prévia compreensão do instituto das patentes, do comércio internacional e do interesse econômico do setor industrial privado se faz necessária, a fim de destacar o drama dos Estados para viabilizar o atendimento da saúde coletiva frente

\footnotetext{
${ }^{10}$ Agência Italiana de Notícias, 2013.

${ }^{11}$ BULASMED. Bulas de Medicamentos. Avastin. Disponível em: <http://www.bulas.med.br/bula/63637/ avastin.htm>. Acesso em: 31 out. 2017.

${ }^{12 N O V A R T I S . ~ L u c e n t i s . ~ D i s p o n i ́ v e l ~ e m: ~<h t t p s: / / p o r t a l . n o v a r t i s . c o m . b r / u p l o a d / i m g c o n t e u d o s / 1511 . p d f>. ~}$ Acesso em: 09 nov. 2015.
} 
aos interesses dos atores de mercado, que representam o setor privado. A compreensão desse conflito de interesses permite pontuar o quão vulnerável encontram-se os sistemas públicos de saúde e os consumidores em relação ao mercado de capital. A situação reporta a imprescindibilidade da regulação do Estado nessas questões que atingem a população: seja do ponto de vista dos destinatários da política, seja do ponto de vista tributário (a imposição de uma maior contribuição financeira por parte da população para "saldar" a conta do preço imposto pelo desejo de lucro das empresas farmacêuticas).

\section{Breve panorama da proteção da propriedade intelectual e assistência farmacêutica}

Nas últimas décadas, a propriedade intelectual passou a ser vista com "outros olhos" pela ordem internacional, agora pautada pelo desenvolvimento econômico e sustentável dos países; - antes disso, a propriedade era medida apenas pelas extensões de terra ou pelas instalações fabris, nos meados da Revolução Industrial. No pós-Revolução Industrial, diversos valores sociais ganharam maior importância e, a exemplo dos direitos humanos, a propriedade intelectual adquiriu prestígio, tanto no âmbito do desenvolvimento comercial como também no humano, cumprindo uma função social ${ }^{13}$. Na concepção do instituto jurídico, a propriedade intelectual expressa uma remuneração ao seu inventor por seu invento.

No Brasil, o direito à propriedade foi reconhecido na Constituição Federal de $1988^{14}(\mathrm{CF} / 88)$ como direito fundamental e é uma das exigências da $\mathrm{OMC}^{15}$, cujo Acordo TRIPS, impôs que todos os seus países signatários respeitassem as patentes e, assim, as regulamentassem em sua base territorial - haja vista que a OMC é responsável por um sistema multilateral de comércio regido por normas e princípios, no qual a propriedade deve exercer sua função social ${ }^{16}$, premiando o inventor com a exploração exclusiva de seu invento. O sistema de patentes foi criado com o intuito de proteger o comércio internacional e os inventores; por meio de uma carta-patente,

${ }^{13}$ CARVALHO, Patrícia Luciane de. Patentes farmacêuticas e acesso a medicamentos. São Paulo: Atlas, 2007.

${ }^{14}$ BRASIL. Constituição da República Federativa do Brasil de 1988. Disponível em: <http://www.planalto.gov. br/ccivil_03/constituicao/constituicaocompilado.htm>. Acesso em: 31 out. 2017.

${ }^{15} \mathrm{~A}$ OMC iniciou suas atividades em $1^{\circ}$ de janeiro de 1995 e, desde então, tem atuado como a principal instância para administrar o sistema multilateral de comércio. A organização tem por objetivo estabelecer um marco institucional comum para regular as relações comerciais entre os diversos membros que a compõem, estabelecer um mecanismo de solução pacífica das controvérsias comerciais, tendo como base os acordos comerciais atualmente em vigor, e criar um ambiente que permita a negociação de novos acordos comerciais entre os membros. Atualmente, a OMC conta com 160 membros, sendo o Brasil um dos membros fundadores. BRASIL. Ministério das Relações Exteriores. Organização Mundial do Comércio. Disponível em: <http://www.itamaraty.gov.br/pt-BR/politica-externa/diplomacia-economica-comercial-efinanceira/132-organizacao-mundial-do-comercio-omc>. Acesso em: 18 ago. 2016.

${ }^{16}$ CARVALHO, Patrícia Luciane de. op. cit. 
os inventores obteriam proveitos financeiros de seus inventos por um período de até 20 anos a partir da data do depósito do pedido de patente ${ }^{17}$.

Com base nessa pré-concepção, foi constituída uma esfera de proteção internacional abrangendo os interesses sociais e os direitos de propriedade, e assim ocorre no caso da proteção às patentes farmacêuticas. A defesa dos direitos humanos e sociais foi primordial na relação entre eles e o comércio internacional: a Organização Mundial da Propriedade Intelectual (OMPI) e a OMC, simultaneamente ao estabelecimento da proteção aos direitos de propriedade, ponderaram uma flexibilização no uso dos inventos para a proteção dos direitos humanos - por exemplo, a necessidade de desenvolvimento e acesso a medicamentos ${ }^{18}$.

$\mathrm{Na}$ prática, porém, a quebra de patentes ${ }^{19}$ não tem sido praticada com frequência pelos países, em nome do respeito ao direito autoral.

A OMC realiza suas articulações por meio de tratados. No que se refere aos medicamentos e ao direito de propriedade intelectual destes, tem-se o Acordo sobre Aspectos dos Direitos de Propriedade Intelectual (TRIPS). Sem delongas sobre as questões históricas que envolvem a discussão sobre propriedade intelectual, podem-se destacar as palavras de Chaves, Oliveira e Hasenclever que sistematizam as características do TRIPS:

O Acordo TRIPS apresenta duas características importantes: primeiro, estabelece regras sobre os direitos de propriedade intelectual, que são mais rígidas do que aquelas vigentes na ocasião nos países desenvolvidos; segundo, não reconhece a liberdade de cada país-membro de adotar um arcabouço legislativo que favoreça o seu desenvolvimento tecnológico ${ }^{20}$.

Ao mesmo tempo em que aumenta a rigidez das regras de proteção da propriedade intelectual, o TRIPS ressalva situações de licença compulsória - que seria uma flexibilização das regras de proteção de invento na área da saúde, favorecendo o acesso a medicamentos e a proteção dos interesses sociais ${ }^{21}$. Porém, há que se ressaltar que a licença compulsória só pode ser emitida: mediante a falta de exploração da patente; em razão do interesse público; em situações de emergência nacional e extrema urgência; para remediar práticas anticompetitivas e de concorrência desleal; por falta de produção local; e na existência de patentes dependentes. No Brasil, a

\footnotetext{
${ }^{17} \mathrm{HEY}$, Raul. Patentes e comércio internacional. Bussiness Review, 12 jun. 2013. Disponível em: <http://www. dannemann.com.br/dsbim/Biblioteca_Detalhe.aspx?\&ID=861\&pp=1\&pi=2> Acesso em: 07 nov. 2015. ${ }^{18}$ CARVALHO, Patrícia Luciane de. op. cit.

${ }^{19}$ No Brasil há registro da quebra de patentes de um medicamento (efavirenz) para tratamento do HVI.

${ }^{20}$ CHAVES, Gabriela Costa; OLIVEIRA, Maria Auxiliadora; HASENCLEVER, Lia; MELO, Luiz Martins de. A evolução do sistema internacional de propriedade intelectual: proteção patentária para o setor farmacêutico e acesso a medicamentos. Cad. Saúde Pública, São Paulo, v. 23, n. 2, p. 257-267. Disponível em: <http:// www.scielo.br/pdf/csp/v23n2/02.pdf>. http://dx.doi.org/10.1590/S0102-311X2007000200002.

${ }^{21}$ CARVALHO, Patrícia Luciane de. op. cit.
} 
licença compulsória está regulamentada no artigo 68 da Lei n. 9.279/1996 (Lei da Propriedade Industrial - LPI), podendo ser concedida em casos de abuso de direitos e poder econômico, bem como quando houver interesse público.

Na prática, percebe-se que, em regra, essa "proteção" confere direitos ao inventor/detentor de forma desproporcional, limitando as possibilidades de licenciamento compulsório, e fere a ordem democrática nacional, formando monopólios no setor farmacêutico e restringindo o acesso a medicamentos que poderiam ser "barateados" se sua produção estivesse em domínio público. Como expõe Petersen a seguir:

O fato de a invenção possuir proteção estatal de exploração econômica por meio do depósito de uma patente produz uma reserva de mercado em relação à produção do invento, que repercute diretamente na inelasticidade do preço pelo qual o bem será comercializado, afinal, haverá um monopólio de produção e comercialização durante a vigência do prazo desta patente. $\mathrm{Na}$ prática isso significa que, a partir do momento do depósito de uma nova droga/medicamento descoberta, ela receberá uma proteção pública de exploração econômica por seu inventor, pelo período de até 20 anos, junto ao mercado de consumo. Se de um lado a legislação concede o direito do inventor à percepção de lucro pelo seu invento, de outro lado, pelo mesmo ato produz o efeito de mitigar o acesso democrático ao bem inventado, o que, por conseguinte, o torna restrito a quem possa pagar seu preço ${ }^{23}$.

A competição econômica existe quando duas ou mais pessoas disputam o mesmo mercado com objetivo de lucro, formando, assim, o sistema concorrencial. Quando esse sistema é eficiente, teoricamente a sociedade irá dispor de melhores produtos com menores preços ${ }^{24}$. Essas circunstâncias, no comércio de medicamentos, trariam benefícios àquela parcela da população que paga por seus tratamentos de saúde e também ao Estado, que poderia ofertar esse bem público a um custo menor.

Cada país faz escolhas políticas e sociais, a exemplo da política de saúde pública no Brasil, que estabeleceu o acesso universal à saúde por meio do SUS e, dentro dele, organizou a Política Nacional de Assistência Farmacêutica (PNAF) a fim de disponibilizar gratuitamente os medicamentos essenciais à saúde da população $0^{25}$. A PNAF elaborou a Rename pautada no critério de racionalidade e essencialidade para atender as necessidades de saúde da população.

\footnotetext{
22 BRASIL. Lei n. 9.279, de 14 de maio de 1996. Regula direitos e obrigações relativos à propriedade industrial. Disponível em: <http://www.planalto.gov.br/ccivil_03/leis/L9279.htm>. Acesso em: 31 out. 2017.

${ }^{23}$ PETERSEN, Letícia Lassen. op. cit.

${ }^{24}$ SQUIZZATO, Ana Carolina. Direito financeiro e econômico. São Paulo: Método, 2013.

${ }^{25}$ PETERSEN, Letícia Lassen. op. cit.
} 
Para a Organização Mundial da Saúde (OMS), consideram-se medicamentos essenciais aqueles que servem para satisfazer as necessidades de atenção à saúde da maioria da população. São selecionados com base em sua relevância para a saúde pública, na evidência sobre sua eficácia e segurança e em estudos comparativos de custo e efetividade, devendo estar disponíveis a todo momento, de forma inesgotável - seguindo a essência da concepção de bem público -, nas quantidades adequadas, nas formas farmacêuticas requeridas e a preços que os indivíduos e a comunidade possam pagar $^{26}$. Os medicamentos objeto da situação de conflito na Itália - Avastin ${ }^{\otimes}$ e Lucentis $^{\oplus}$ - não possuem cobertura em saúde pública (via Política de Assistência Farmacêutica) nem no Brasil nem na Itália para o tratamento de DMRI, mas em ambos os países eram fornecidos devido a determinações judiciais que assim obrigavam os entes públicos.

O fundamento das decisões judiciais no Brasil recai sobre a interpretação ampliativa do conceito de essencialidade das prestações públicas de saúde relacionadas ao alcance de medicamentos. A CF/88 instituiu o direito à saúde como um direito universal, na perspectiva de acolher toda a população. As decisões judiciais, porém, interpretam que o acesso universal inclui o fornecimento de todos os tratamentos prescritos por profissionais médicos - mesmo havendo tratamentos alternativos disponibilizados no sistema público.

A consequência desse ativismo judicial gera a obrigatoriedade do fornecimento de medicamentos que não estão incluídos na Relação Nacional de Medicamentos, a exemplo do Lucentis ${ }^{\circledast}$. Tanto a discussão da inclusão dos medicamentos nas listas públicas como o "garantismo" da política "sentenciado" pelo Poder Judiciário em nome do direito individual atraem o setor privado, de tal sorte que o fornecimento de medicamentos por essa via é garantia de venda e obtenção de lucros para o setor.

Note-se que, no caso em análise, o interesse pelo proveito econômico oriundo do depósito duplo da patente motivou a atitude das empresas envolvidas, pois essa prática permitiu extrapolar a obtenção de lucros por meio da expansão do tempo do monopólio de produção. Fraudar o sistema econômico em busca de lucro é uma questão ética, que precisa ser enfrentada pelos Estados que aderem ao sistema econômico capitalista, especialmente quando o objeto da fraude envolve o financiamento e o interesse públicos - tal como a situação elencada, que atingiu tanto consumidores como o sistema público de saúde.

A ocorrência dessa fraude remete-se à revisão do rigor com que se conduzem os depósitos de patentes de medicamentos e sua exploração. A situação escancara a necessidade de os Estados-Nações voltarem suas discussões para a adoção de medidas que limitem os interesses do capital frente às necessidades de promoção da vida, como é o acesso a medicamentos. Além disso, reporta ao reforço do rigor e

\footnotetext{
${ }^{26}$ CARVALHO, Patrícia Luciane de. op. cit.
} 
da seriedade que devem conduzir a fiscalização e o acompanhamento técnico para permissão da distribuição de medicamentos nos mercados nacionais, bem como a efetiva adoção de licenciamento compulsório nos casos em que os interesses pelo lucro apresentarem indícios de constituir barreiras ao acesso a tratamentos.

No que se refere à ação criminosa de prática de conluio apurada pela Itália, existem fortes indícios da ocorrência dessa conduta em âmbito mundial, uma vez que as bulas dos medicamentos envolvidos na fraude italiana foram registradas de igual modo no Brasil, com indicações idênticas às italianas, como se demonstrará a seguir.

\section{Situação do registro dos medicamentos Avastin $₫$ e Lucentis $\AA^{\circledR}$ no Brasil e seu financiamento público}

No Brasil, conforme pesquisa no site da Anvisa acerca da aprovação das bulas dos medicamentos em questão, verifica-se uma possível reprodução do caso italiano, uma vez que a submissão das bulas dos medicamentos apresenta a seguinte condição:

(a) o fármaco Avastin (bevacizumabe) requisitou e obteve sua aprovação para o tratamento oncológico; este medicamento possui um anticorpo monoclonal humanizado que inibe o crescimento tumoral;

(b) o fármaco Lucentis ${ }^{\circ}$ (ranibizumabe) requisitou e obteve sua aprovação para reduzir o crescimento e o vazamento de novos vasos no olho, processos anormais que contribuem para a progressão da forma úmida da DMRI e o desenvolvimento de edema macular (inchaço) devido à diabetes (edema macular diabético - EMD) ou oclusão de veia retinal (OVR).

A inclusão do Lucentis ${ }^{\circledast}$ na Rename também já havia sido solicitada junto ao órgão de avaliação e incorporação de tecnologias, a Comissão Nacional de Incorporação de Tecnologias no SUS (Conitec, criada pela Lei n. 12.401/201127). Nesta esfera, verifica-se que o medicamento Lucentis ${ }^{\bullet}$ (ranibizumabe) já teve diversas submissões para incorporação no sistema público de saúde. Contudo, após pesquisas e estudos, os membros da Conitec recomendaram a não incorporação, por considerarem suficientes as alternativas disponíveis no sistema com a mesma finalidade de tratamento indicada em sua bula. No parecer dessa instância, já foi apontada a semelhança do sal do fármaco Lucentis ${ }^{\circledast}$ com o do Avastin ${ }^{\circledR}$. Cumpre referir que a inclusão do Avastin ${ }^{\circledR}$ não foi objeto de avaliação por parte da Conitec porque a pactuação dos medicamentos oncológicos confere certa liberdade ao gestor na escolha dos tratamentos que serão disponibilizados por sua equipe profissional, havendo transferência de recursos por parte do Ministério da Saúde na maioria dos casos.

${ }^{27}$ BRASIL. Lei n. 12.401, de 28 de abril de 2011. Altera a Lei n ${ }^{\circ} 8.080$, de 19 de setembro de 1990, para dispor sobre a assistência terapêutica e a incorporação de tecnologia em saúde no âmbito do Sistema Único de Saúde - SUS. Disponível em: <http://www.planalto.gov.br/ccivil_03/_ato2011-2014/2011/lei/ I12401.htm>. Acesso em: 31 out. 2017. 
A Política Nacional de Medicamentos (Portaria n. 3.916/1988 ${ }^{28}$ ), tem por objetivos: a adoção da Rename; a regulamentação sanitária de medicamentos; a reorientação da assistência farmacêutica; a promoção do uso racional de medicamentos; entre outros. A Rename preconiza a segurança, a qualidade e a eficácia dos medicamentos a menores custos, suscitando o uso racional e o acesso dos cidadãos aos medicamentos considerados essenciais ${ }^{29}$.

Apesar da criteriosa organização da Rename, composta por um elenco racional de medicamentos considerados essenciais, o acesso dos cidadãos a medicamentos não está restrito a essa lista. Dessa forma, todo medicamento que se fizer necessário para uma vida digna deve ter o acesso garantido pelo Estado, conforme preveem a norma constitucional e os critérios de disponibilização ${ }^{30}$.

Embora os medicamentos sob análise não estejam previstos nas listas da política pública, frequentemente são objeto de demandas judiciais por parte dos pacientes contra os sistemas de saúde municipais e/ou estaduais de saúde em diversos tribunais do país.

Com isso, afere-se que os cofres públicos dos entes federados no Brasil estão sendo onerados do mesmo modo que ocorrera na Itália, em nome do patrocínio do interesse financeiro do setor privado farmacêutico, via processo de judicial. As decisões via sistema de Justiça que obrigaram o ente público, em sua maioria, não levam em consideração a arquitetura da política de saúde e os pareceres do órgão técnico (Conitec) que se dedica à avaliação individual do medicamento, privilegiando os interesses privados em escancarado detrimento da organização coletiva proposta pela política.

\section{0 arcabouço jurídico brasileiro para tentar coibir os embates da indústria farmacêutica}

O Estado democrático brasileiro possui como princípio fundamental o direito à saúde e, para que esse direito esteja assegurado, faz-se necessário o acesso aos medicamentos. Consequentemente, esse setor possui uma grande demanda e supostamente muitas falhas de mercado, sendo necessária uma efetiva regulação. Para isso, o Estado precisa regular tanto a venda dos medicamentos quanto o acesso a eles por meio da política de saúde; e, para enfrentar a questão econômica, o fez por meio de uma estrutura técnica vinculada ao Ministério da Saúde, aos conselhos de saúde e às agências reguladoras.

\footnotetext{
${ }^{28}$ MINISTÉRIO DA SAÚDE. Portaria n. 3.196, de 30 de outubro de 1988. Disponível em: <http://bvsms.saude. gov.br/bvs/saudelegis/gm/1998/prt3916_30_10_1998.html>. Acesso em: 31 out. 2017.

${ }^{29}$ CARVALHO, Patrícia Luciane de. op. cit.

${ }^{30}$ Id. Ibid.
} 
Os economistas constataram que o setor de medicamentos possui várias características que prejudicam e impedem a concorrência efetiva do mercado, quais sejam: a essencialidade do produto, tendo como principal consequência a baixa elasticidade da demanda e o poder de mercado conferido aos produtores; a existência de barreiras à entrada de medicamentos no país (as patentes, as vantagens da escala em pesquisa e desenvolvimento $[\mathrm{P} \& \mathrm{D}]$ e a lealdade à marca), pois, para que um medicamento seja comercializado no Brasil, faz-se necessário o registro na Anvisa e a aprovação do preço pela Câmara de Regulação de Mercado de Medicamentos $(\mathrm{CMED})^{31}$.

Para Gatto, os investimentos em P\&D constituem barreiras à entrada da indústria nacional no mercado, uma vez que os medicamentos inovadores desenvolvidos pelas transnacionais podem ser patenteados no Brasil. Ainda que a patente por si só seja considerada uma barreira à entrada, os defensores da meritocracia do capital aspiram a ela como fundamental para garantir a novidade do setor. Ademais, a lealdade à marca é resultado da confusão de informações, prejudicando os consumidores, que muitas vezes dispõem de informações pobres sobre a disponibilidade, o preço e a qualidade dos medicamentos que podem ser substitutos. Tal fato se confirma pelos significativos gastos das empresas com publicidade para lançar seus produtos no mercado ${ }^{32}$.

Diante de tais considerações, visível é a vulnerabilidade por parte do consumidor diante dos fornecedores, muitas vezes restringindo até o direito ao consumo, o que reforça a necessidade de intensa regulação do setor de medicamentos ${ }^{33}$.

No Brasil, a norma legitima as patentes por meio do INPI. Contudo, faz-se necessária uma anuência prévia da Anvisa, para posterior avaliação e decisão dos processos de patentes pelo INPI, conforme segue:

Se a Agência conceder a anuência, o pedido retornará ao INPI para que seja dado seguimento ao processo de avaliação. Caso a Anvisa não conceda a anuência prévia, o pedido de patente será arquivado e a decisão, publicada na Revista de Propriedade Industrial [...] De acordo com o artigo 229-C da Lei 9.279/96, a concessão de patentes para produtos e processos farmacêuticos depende da anuência prévia da Anvisa. Este mecanismo foi criado de forma a aproximar o direito à propriedade intelectual das políticas públicas de saúde e igualdade social vigentes no Brasil ${ }^{34}$.

${ }^{31}$ GATTO, Ana Carolina dos Santos; OLIVEIRA, Amanda Flávio de. Direito econômico: evolução e institutos. Rio de Janeiro: Forense, 2009.

${ }^{32}$ Id. Ibid.

${ }^{33}$ Id. Ibid.

${ }^{34}$ COMISSÃO NACIONAL DE INCORPORAÇÃO DE TECNOLOGIAS NO SUS - CONITEC. Decisões sobre a incorporação de tecnologias no SUS - 2012. Disponível em: <http://conitec.gov.br/index.php/decisoessobre-a-incorporacao-de-tecnologias-no-sus-2012>. 
Ainda que o direito de propriedade esteja garantido pelo artigo $5^{\circ}$, inciso XXII, da $\mathrm{CF} / 88^{35}$, sendo um dos pilares dos direitos fundamentais da pessoa humana, $\mathrm{o}$ artigo 170, da mesma ordem constitucional, traz um rol de princípios propostos para a regulação da atividade econômica, dentre os quais tem destaque o inciso III, que estabelece a função social da propriedade - embora não definida no texto constitucional, é evidente que são os interesses públicos e sociais que devem ser considerados. Para Roberto Ferreira, "a função social da propriedade é princípio posto na ordem econômica constitucional para temperar propostas jurídicas de tutela desse instituto, garantindo a titularidade de toda e qualquer espécie de propriedade legalmente constituída ${ }^{36 "}$.

Nesse sentido, o medicamento reveste-se de essencialidade à promoção da vida, e a proteção à proteção da propriedade intelectual merece sopesar os valores conflitantes quando se está diante de situações que o tornam necessário, mas inacessível materialmente.

Em 1994 o Brasil passou a adotar as medidas necessárias e orientadas pela OMC para proteger os inventos industriais, adaptando, assim, sua legislação depois de firmar o Acordo TRIPS ${ }^{37}$.

Assim, seguindo orientações internacionais, o Brasil elaborou o Decreto n. $1.335 / 1994^{38}$, por meio do qual regulamentou o uso de inventos e propriedades no sistema normativo nacional, acolhendo os resultados da Rodada do Uruguai de negociações comerciais multilaterais do GATT. Aproximadamente dois anos, foi aprovada a Lei n. 9.279/ $1996^{39}$ (LPI) -, que estabeleceu no âmbito nacional a integralidade das normas e dos direitos anteriormente firmados no TRIPS no que se referem à propriedade industrial ${ }^{40}$.

O fato de estar diretamente relacionado à criação científica de algo novo enquadra o medicamento no conceito de invenção, protegido pela LPI - o que confere a esse bem proteção pública ao invento e às adaptações necessárias até o produto final. Porém, essa proteção estatal, pelo depósito da patente, produz uma restrição ao mercado em relação à produção do invento, repercutindo diretamente na inelasticidade do preço e tornando restrito o acesso de quem o possa pagar, conforme evidencia Petersen:

A Lei de Propriedade Industrial sistematiza, em seu art. 40, o prazo de proteção estatal à invenção e ao modelo de utilidade, nos seguintes termos - A patente de invenção vigorará pelo prazo de

\footnotetext{
${ }^{35}$ BRASIL. Constituição da República Federativa do Brasil, cit.

${ }^{36}$ FERREIRA, Roberto; MACHADO, Costa; FERRAZ, Anna Candida da Cunha. Constituição Federal interpretada. 3. ed. São Paulo: Manole, 2012.

${ }^{37}$ CARVALHO, Patrícia Luciane de. op. cit.

${ }^{38}$ BRASIL. Decreto n. 1.335, de 30 de dezembro de 1994. Promulgo a Ata Final que Incorpora os Resultados da Rodada Uruguai de Negociações Comerciais Multilaterais do GATT. Disponível em: <http://www.planalto. gov.br/ccivil_03/decreto/antigos/d1355.htm>. Acesso em: 31 out. 2017.

${ }^{39}$ BRASIL. Lei $n$. 9.279, de 14 de maio de 1996, cit.

${ }^{40}$ PETERSEN, Letícia Lassen. op. cit.
} 
20 (vinte) anos e a de modelo de utilidade, pelo prazo 15 (quinze) anos contados da data de depósito". O entendimento jurídico que existe sobre o assunto afirma que este prazo de 20 anos começa a vigorar a partir do primeiro depósito da invenção realizado pela indústria. Portanto, acaso o Brasil não seja o primeiro país a receber o depósito do bem, objeto da invenção, o parágrafo único do artigo anteriormente referido ainda concede um período de proteção pública ao invento, nos seguintes termos: "o prazo de vigência não será inferior a $10(\mathrm{dez})$ anos para a patente de invenção e a 7 (sete) anos para a patente de modelo de utilidade, a contar da data de concessão, ressalvada a hipótese de o INPI estar impedido de proceder ao exame de mérito do pedido, por pendência judicial comprovada ou por motivo de força maior”. Tal circunstância acaba por trazer uma inelasticidade ao bem medicamento enquanto uma invenção sujeita à proteção industrial, e pode impactar a incorporação de tecnologias em saúde pública ${ }^{41}$.

O artigo 31 do Acordo TRIPS ${ }^{42}$ prevê formas de flexibilização quando se trata de interesse de saúde pública. Uma delas é a licença compulsória, conhecida popularmente como "quebra de patentes", que "consiste na autorização concedida pelo Estado para o uso da invenção patenteada sem o consentimento do detentor da patente. Trata-se de uma potencial estratégia para regular o monopólio ocasionado pela proteção patentária" ${ }^{43}$. Assim, havendo conflitos de interesses públicos e privados, o Acordo TRIPS, em seu regulamento, permite que o Estado faça uso dos instrumentos jurídicos para obter a licença compulsória.

Para que a licença compulsória seja requisitada, faz-se necessária uma justificativa plausível e fundamentada, ou seja, deve haver interesse público/emergência nacional para sua concessão. Além do mais, a legislação do país signatário tem de prever em legislação específica as situações possíveis para a concessão da quebra de patente, devendo haver interesse público ou emergência nacional - no Brasil, regulamentados pelos Decretos n. $3.201 / 1999^{44}$ e n. $4.830 / 2003^{45}$.

\footnotetext{
${ }^{41}$ PETERSEN, Letícia Lassen. op. cit.

${ }^{42}$ INSTITUTO NACIONAL DE PROPRIEDADE INTELECTUAL. Decreto $n$. 1.355, de 30 de dezembro de 1994, cit. ${ }^{43}$ CHAVES, Gabriela Costa. Patentes farmacêuticas. Por que dificultam o acesso a medicamentos? Rio de Janeiro: ABIA, 2006. Disponivel em: <http://abiaids.org.br/_img/media/cartilha_patentes.pdf>. Acesso em: 31 out. 2017.

${ }^{44}$ BRASIL. Decreto n. 3.201, de 6 de outubro de 1999. Dispõe sobre a concessão, de ofício, de licença compulsória nos casos de emergência nacional e de interesse público de que trata o art. 71 da Lei $n^{\circ}$ 9.279, de 14 de maio de 1996. Disponível em: <https://www.planalto.gov.br/ccivil_03/decreto/d3201. htm>. Acesso em: 31 out. 2017.

${ }^{45}$ BRASIL. Decreto n. 4.830, de 4 de setembro de 2003. Dá nova redação aos arts. $1^{\circ}, 2^{\circ}, 5^{\circ}, 9^{\circ}$ e 10 do Decreto $n^{\circ} 3.201$, de 6 de outubro de 1999, que dispõe sobre a concessão, de ofício, de licença compulsória nos casos de emergência nacional e de interesse público de que trata o art. 71 da Lei $n^{\circ}$ 9.279, de 14 de maio de 1996. Disponível em: <http://www.planalto.gov.br/ccivil_03/decreto/2003/d4830.htm>. Acesso em: 31 out. 2017.
} 
Na Lei brasileira de Propriedade Industrial no 9.279/96, por exemplo, a licença compulsória está prevista dos artigos 68 a 74. Neles estão incluídas as possibilidades de concessão de licença compulsória por falta de exploração da patente, por interesse público, em casos de emergência nacional, para remediar práticas anticompetitivas, por falta de fabricação local da patente e em situações nas quais a exploração de uma patente dependa de outra (patentes dependentes) $[\ldots]^{46}$.

A concessão de patentes de produtos farmacêuticos no Brasil exige a aprovação prévia da Anvisa, conforme artigo 229-C da Lei n. 10.196/2001"47: "A concessão de patentes para produtos e processos farmacêuticos dependerá da prévia anuência da Agência Nacional de Vigilância Sanitária - ANVISA (NR)”.

O Capítulo VI, Título V, da LPI ${ }^{48}$ prevê os crimes de concorrência desleal, sendo que o artigo 195 elenca o rol desses crimes. Também prevê sanções pela prática desses crimes: detenção de três meses a um ano ou multa, sendo que essas penalidades poderão ser aumentadas.

Para a ordem econômica nacional, a prática do cartel é considerada a mais grave lesão à livre concorrência. Há muito tempo condenado em nosso país, essa prática prejudica os consumidores ao aumentar o preço e reduzir a oferta, tornando bens e serviços muito caros ou indisponíveis no mercado ${ }^{49}$.

Apesar da gravidade da prática de cartel, foi apenas em 1994, com a publicação da Lei Antitruste (Lei n. 8.884/1994), que o Brasil legislou sobre o assunto. Esta lei abordava a prevenção e a repressão às infrações contra a ordem econômica. Atualmente, a matéria está regulada na Lei n. 12.529/2011 ${ }^{50}$ (Lei de Defesa da Concorrência ou Lei Antitruste). A Lei Antitruste possui aplicabilidade de ordem internacional, podendo ser aplicada nos tratados ou convenções internacionais de que o Brasil for signatário.

\footnotetext{
${ }^{46}$ CHAVES, Gabriela Costa. op. cit., p. 21.

${ }^{47}$ BRASIL. Lei n. 10.196, de 14 de fevereiro de 2001. Altera e acresce dispositivos à Lei $n^{\circ}$ 9.279, de 14 de maio de 1996, que regula direitos e obrigações relativos à propriedade industrial, e dá outras providências. Disponível em: <http://www.planalto.gov.br/ccivil_03/leis/LEIS_2001/L10196.htm>. Acesso em: 31 out. 2017.

${ }^{48}$ BRASIL. Lei n. 9.279, de 14 de maio de 1996, cit.

${ }^{49}$ SQUIZZATO, Ana Carolina. op. cit.

${ }^{50}$ BRASIL. Lei n. 12.529, de 30 de novembro de 2011. Estrutura o Sistema Brasileiro de Defesa da Concorrência; dispõe sobre a prevenção e repressão às infrações contra a ordem econômica; altera a Lei n ${ }^{\circ} 8.137$, de 27 de dezembro de 1990, o Decreto-Lei n 3.689, de 3 de outubro de 1941 - Código de Processo Penal, e a Lei $n^{\circ} 7.347$, de 24 de julho de 1985; revoga dispositivos da Lei $n^{\circ} 8.884$, de 11 de junho de 1994, e a Lei n 9.781, de 19 de janeiro de 1999; e dá outras providências. Disponível em: <http://www.planalto.gov.br/ ccivil_03/_ato2011-2014/2011/Lei/L12529.htm>. Acesso em: 31 out. 2017.
} 
Segundo Bagnoli $i^{51}$, a Secretaria de Desenvolvimento Econômico (SDE), em sua cartilha de Combate a Cartéis e Programa de Leniência ${ }^{52}$, define cartel como "um acordo explícito ou implícito entre concorrentes para, principalmente, fixação de preços ou quotas de produção, divisão de clientes e de mercados de atuação". No sentido de coibir a prática da concorrência desleal, a Lei Antitruste definiu limitações com panorama constitucional para a defesa da concorrência, qual seja a repressão ao abuso do poder econômico que vise: à dominação dos mercados; à eliminação da concorrência e ao aumento arbitrário dos lucros.

Para isso, o Sistema Brasileiro de Defesa da Concorrência (SBDC), conforme prevê o artigo $3^{\circ}$ da Lei de Defesa de Concorrência ${ }^{53}$, é formado pelo Conselho Administrativo de Defesa Econômica (Cade) - órgão judicante vinculado ao Ministério da Justiça - e pela Secretaria de Acompanhamento Econômico do Ministério da Fazenda (SEAE/MF) - órgão técnico vinculado ao Ministério da Fazenda. O SBDC desenvolve três ações consideradas essenciais, quais sejam: ação preventiva - controle de estruturas de mercado; ação repressiva - repressão a condutas anticompetitivas, como por exemplo, a formação de cartéis; e ação educativa - propalando a cultura da livre concorrência ${ }^{54}$.

A Lei Lei Antitruste, em seu artigo 36, apresenta o rol de infrações à ordem econômica, optando por uma visão ampla e vaga dessas infrações - denominada tipicidade aberta - a fim de abranger o maior número de ações lesivas possível. No parágrafo $3^{\circ}$ do próprio artigo 36 , elenca um rol exemplificativo de inúmeras condutas lesivas à ordem econômica ${ }^{55}$.

Assim, no caso de ocorrência da prática de cartel em território brasileiro, conforme o ordenamento jurídico vigente, procedimentos administrativos para prevenção, apuração e repressão de infrações à ordem econômica seriam instaurados, como prevê o artigo 48 da Lei Antitruste. Ainda, se confirmada a prática de infração à ordem econômica, os responsáveis estariam sujeitos às penas previstas nos artigos 37 a 45, Capítulo III da referida lei.

Além da Lei Antitruste, existe no Brasil uma intensa regulação normativa do setor de medicamentos, a fim de viabilizar a concretude dos princípios fundamentais de proteção à vida. Devido ao escasso investimento em pesquisa e consolidação de uma indústria farmacêutica pública, a regulação do setor é a principal forma de o Estado

\footnotetext{
${ }^{51}$ BAGNOLI, Vicente. Direito econômico. 4. ed. São Paulo: Atlas, 2010.

${ }^{52}$ CONSELHO ADMINISTRATIVO DE DEFESA ECONÔMICA - CADE. Combate a cartéis e programa de leniência.

3. ed. Brasília-DF, 2009. p. 6. Disponível em: <http://www.cade.gov.br/acesso-a-informacao/publicacoesinstitucionais/documentos-da-antiga-lei/cartilha_leniencia.pdf>. Acesso em: 31 out. 2015.

${ }^{53}$ BRASIL. Lei n. 12.529, de 30 de novembro de 2011, cit.

${ }^{54}$ SQUIZZATO, Ana Carolina. op. cit.

${ }^{5}$ Id. Ibid.
} 
intervir na economia, com vistas a atingir minimante os objetivos traçados na política econômica, social e administrativa, otimizando o funcionamento da economia ${ }^{56}$.

O objetivo da regulação do setor de medicamentos não é apenas econômico, pois, também recai sobre o acesso da população aos medicamentos, aferindo sua qualidade e a prática de preços viáveis, sem abusos por parte do fornecedor - especialmente em casos de vigência de patentes. Essa intervenção é essencial para que os cidadãos tenham acesso a um bem de consumo frequentemente necessário à promoção da saúde.

Para efetivar especificamente a função de regulação do setor de medicamentos, o Estado atua por meio da administração direta do Ministério da Saúde e por meio de uma autarquia, a Anvisa, que dispõe de um corpo técnico qualificado para atuação - o que constitui um grande avanço para a regulação do setor. O Ministério da Saúde tem o dever, em nome do acesso a medicamentos, de regulamentar e inspecionar as indústrias farmacêuticas e farmoquímicas, sempre considerando as resoluções que são acordadas pelos países signatários no âmbito do Mercosul ${ }^{57}$.

Além do Ministério da Saúde e da Anvisa, existe um órgão específico para a avaliação de novas tecnologias em saúde, que analisa os pedidos de incorporação no sistema público de saúde: a Conitec, responsável pela avaliação e incorporação de novas tecnologias no SUS, criada pela Lei n. $12.401 / 2011^{58}$ - a qual trata sobre a assistência terapêutica e a incorporação de tecnologia em saúde no âmbito do SUS.

Importante repetir que a Conitec não aprovou o uso do Lucentis ${ }^{\circledast}$ no SUS. Emitiu parecer desfavorável ao uso da droga, pois o corpo técnico desse órgão - responsável pela listagem, pela análise e pelo estudo de medicamentos que compõem a Rename - julgou que os tratamentos que já estão presentes na Rename são seguros e eficazes para o quadro diagnóstico sugerido pela farmacêutica ${ }^{59}$ (DMRI).

A Conitec tem papel fundamental na regulação dos medicamentos, pois as análises e os estudos referentes a segurança, qualidade e eficácia são de responsabilidade desse espaço técnico decisório, conforme expõe Petersen:

Conforme a Lei n. 12.401, a CONITEC é vinculada à Secretaria de Ciência, Tecnologia e Insumos Estratégicos (SCTIE), que pertence ao Ministério da Saúde. Ela é assistida pelo Departamento de Gestão e Incorporação de Tecnologias em Saúde. Os relatórios de análise dos pedidos de incorporação de tecnologias junto ao SUS resultam em documentos públicos que ficam a disposição para consulta. Neles são justificados os motivos que fundamentam a disponibilização ou a não inclusão para a oferta do bem em saúde pública. Estes relatórios são elaborados a partir

\footnotetext{
${ }^{56}$ GATTO, Ana Carolina dos Santos; OLIVEIRA, Amanda Flávio de. op. cit.

${ }^{57}$ CARVALHO, Patrícia Luciane de. op. cit.

${ }^{58}$ BRASIL. Lei $n$. 12.401, de 28 de abril de 2011, cit.

${ }^{59}$ PETERSEN, Letícia Lassen. op. cit.
} 
de sistematizações científicas, em que se analisam a segurança e eficácia do insumo consultado, a existência de insumos ou alternativas disponibilizadas no SUS, a superioridade ou não deste insumo em comparação aos disponibilizados no elenco e o custo ${ }^{60}$.

Outra forma ainda de regulação do mercado farmacêutico é a Câmara de Regulação de Mercado de Medicamentos ${ }^{61}$ (CMED), órgão interministerial responsável por regular o mercado e estipular regras para a definição e a harmonia dos preços dos medicamentos que serão praticados tanto na venda particular quanto nas vendas aos entes públicos. Sua atuação objetiva afasta a possibilidade de ocorrência de fraude ou um desnível de mercado, que permitira que as grandes indústrias farmacêuticas aniquilassem as de menor potencial econômico.

O Ministério da Saúde possui um vasto arcabouço normativo no que se refere à organização do comércio específico de medicamentos. Esse arcabouço inclui desde a concessão do registro no depósito da patente até a pós-comercialização dos medicamentos - quando a CMED fiscaliza o preço médio de mercado desses bens.

Contudo, existem fortes indícios de que possa ter ocorrido no Brasil fraude semelhante à registrada em território italiano, pois o registro das bulas aqui foi o mesmo feito na Itália. Contudo, mesmo após a notícia da fraude na Itália repercutir mundialmente, não existe notícia da adoção de medidas para apurar a situação no Brasil. Normas não faltam para a adoção de medidas de punição e ressarcimento dos gastos efetivados pelo poder público relativos ao pagamento indevido da patente do medicamento Lucentis ${ }^{\circledast}$.

\section{Considerações finais}

Longe de chegar ao final, a discussão em que se pontuam conflitos entre os interesses públicos e privados ressalta a importância da atuação do Estado na ordem econômica, especialmente para preservar a saúde da população. O caso das farmacêuticas que, em nome do lucro, registraram duas vezes o mesmo sal para finalidades distintas de tratamento com o objetivo de prolongar a vigência da patente, demonstra a importância do olhar atento dos Estados nacionais sobre a regulação da economia.

A partir da descrição da situação italiana, apurada pela via documental e de mídia, associada à apuração dos registros dos medicamentos Avastin ${ }^{\circledast}$ e Lucentis ${ }^{\circledast}$ no Brasil, verificam-se fortes indícios de que a situação vivenciada na Itália se reproduz no território brasileiro. Desse modo, o Brasil, a exemplo da Itália e levando em consideração

\footnotetext{
${ }^{60}$ PETERSEN, Letícia Lassen. op. cit.

${ }^{61}$ AGÊNCIA NACIONAL DE VIGILÂNCIA SANITÁRIA - ANVISA. Câmara de Regulação do Mercado de Medicamentos - CMED. Disponível em: <http://portal.anvisa.gov.br/wps/content/Anvisa+Portal/Anvisa/ Pos+-+Comercializacao+-+Pos+-+Uso/Regulacao+de+Marcado>. Acesso em: 07 nov. 2015.
} 
a construção normativa que reprime a prática de cartel, deveria adotar as medidas necessárias para apurar e reprimir eventual conluio - apurando se é caso de ressarcimento dos cofres públicos, frente aos gastos realizados para a promoção da saúde na aquisição do fármaco Lucentis ${ }^{\oplus}$, e retirando a vigência de sua patente. Os indícios apontam para a uniformização da conduta das indústrias na prática do registro desses medicamentos. A hipótese de pesquisa restou confirmada: existem fortes indícios de que a fraude descoberta pelo Estado italiano também esteja ocorrendo no Brasil.

O estudo apresentado neste artigo foi pontual e comparado, restringindo-se aos medicamentos Avastin ${ }^{\circledast}$ e Lucentis ${ }^{\circledast}$. A pesquisa realizada deixa em aberto muitos questionamentos acerca do repensar da organização dos Estados na orientação da economia - especialmente nas searas que dizem respeito à vigilância sanitária, que repercutem diretamente na saúde da população. A fragilidade dos sujeitos só pode ser afastada com a atuação de um Estado forte e operante. A omissão e inoperância dos Estados em relação ao interesse do capital internacional oprimem e expõem a vida da população aos interesses do mercado. Os interesses privados criam e recriam caminhos para transpassar os interesses de proteção aos direitos humanos e fundamentais.

Em tempos de discussão da autorregulação da economia, estudos de caso como este demonstram a necessidade da adoção de medidas que busquem o equilíbrio entre os interesses públicos e os privados. Tais medidas são viáveis apenas com a construção de um Estado sério, ético, capaz de frear a busca de lucro a qualquer custo, que proteja a concepção de cidadania e a estrutura de promoção da cidadania que consolidou.

\section{Referências}

AGÊNCIA NACIONAL DE SAÚDE SUPLEMENTAR - ANS. Histórico. Disponível em: <http://www.ans.gov.br/aans/quem-somos/historico>. Acesso em: 10 nov. 2015.

AGÊNCIA NACIONAL DE VIGILÂNCIA SANITÁRIA - ANVISA. A Agência. Disponível em: <http://portal.anvisa.gov.br/wps/portal/anvisa/anvisa/agencia/!ut/p/ c5/04_SB8K8xLLM9MSSzPy8xBz9CP0os3hnd0cPE3MfAwMDMydnA093Uz8z00B_ A3cPQ6B8JE55A38jYnQb4ACOBgR0e-lHZSbl6pUn5-oZ6JmaGhoYWlgaGpoYm5pamu mHg7yC32kgeTyW-3nk56bqF-SGRIQGB6QDAESGAaI!/?1 dmy\&urile=wcm\%3apath\% 3a/anvisa+portal/anvisa/agencia/publicacao+agencia/a+agencia $>$. Acesso em: 17 out. 2015.

. Atuação internacional da Anvisa. Disponível em: <http://portal.anvisa.gov.br/wps/ content/Anvisa+Portal/Anvisa/Agencia/Assunto+de+Interesse/Relacoes+Internacionais/At uacao+Internacional+da+Anvisa>. Acesso em: 17 out. 2015.

Câmara de Regulação do Mercado de Medicamentos - CMED. Disponível em: <http:// portal.anvisa.gov.br/wps/content/Anvisa+Portal/Anvisa/Pos+-+Comercializacao+-+Pos++Uso/Regulacao+de+Marcado >. Acesso em: 07 nov. 2015. 
AGÊNCIA NACIONAL DE VIGILÂNCIA SANITÁRIA - ANVISA. Regulação Sanitária. Disponível em: <http://portal.anvisa.gov.br/wps/portal/anvisa/anvisa/regulacaosanitaria $>$. Acesso em: 26 maio 2015.

AGUILLAR, Fernando Herren. Direito econômico: do direito nacional ao direito supranacional. 2. ed. São Paulo: Atlas, 2009.

BAGNOLI, Vicente. Direito econômico. 4. ed. São Paulo: Atlas, 2010.

BRASIL. Ministério da Saúde. Ranibizumabe para Degeneração Macular Relacionada à idade. Relatório de Recomendação da Comissão Nacional de Incorporação de Tecnologias no SUS - CONITEC. Disponível em: <http://conitec.gov.br/images/Consultas/Relatorios/2014/ Relatorio_Ranibizumabe-DMRI-CP.pdf>. Acesso em: 01 nov. 2015.

Ministério das Relações Exteriores. Organização Mundial do Comércio. Disponível em: <http://www.itamaraty.gov.br/pt-BR/politica-externa/diplomaciaeconomica-comercial-e-financeira/132-organizacao-mundial-do-comercio-omc $>$. Acesso em: 18 ago. 2016.

BULASMED. Bulas de Medicamentos. Avastin. Disponível em: <http://www.bulas.med.br/ bula/63637/avastin.htm>. Acesso em: 31 out. 2017.

CARVALHO, Patrícia Luciane de. Patentes farmacêuticas e acesso a medicamentos. São Paulo: Atlas, 2007.

CHAVES, Gabriela Costa. Patentes farmacêuticas. Por que dificultam o acesso a medicamentos? Rio de Janeiro: ABIA, 2006. Disponível em: <http://abiaids.org.br/_img/media/cartilha_ patentes.pdf $>$. Acesso em: 31 out. 2017.

; OLIVEIRA, Maria Auxiliadora; HASENCLEVER, Lia; MELO, Luiz Martins de. A evolução do sistema internacional de propriedade intelectual: proteção patentária para o setor farmacêutico e acesso a medicamentos. Cad. Saúde Pública, São Paulo, v. 23, n. 2, p. 257-267. Disponível em: <http://www.scielo.br/pdf/csp/v23n2/02.pdf>. http://dx.doi.org/10.1590/ S0102-311X2007000200002.

COMISSÃO NACIONAL DE INCORPORAÇÃO DE TECNOLOGIAS NO SUS - CONITEC. A comissão. Disponível em: $<$ http://conitec.gov.br/index.php/2014-08-07-13-22-56 >. Acesso em: 07 nov. 2015.

Decisões sobre a incorporação de tecnologias no SUS - 2012. Disponível em: <http:// conitec.gov.br/index.php/decisoes-sobre-a-incorporacao-de-tecnologias-no-sus-2012>.

CONSELHO ADMINISTRATIVO DE DEFESA ECONÔMICA - CADE. Combate a cartéis e programa de leniência. 3. ed. Brasília-DF, 2009. Disponível em: <http://www. cade.gov.br/acesso-a-informacao/publicacoes-institucionais/documentos-da-antiga-lei/ cartilha_leniencia.pdf $>$. Acesso em: 31 out. 2015. 
O público e o privado, as patentes e a saúde na Itália e no Brasil

EUROPEAN PARLAMENT. Links between pharmaceutical R\&D models and Access to Affordable Medicines. European Union: 2014. Disponível em: <http://www.europarl.europa. eu/supporting-analyses $>$. Acesso em 24 de mar. 2017.

Links between pharmaceutical R\&D models and access to affordable medicines. Directorate General for Internal Policies Policy Department a: Economic and Scientific Policy, 2016. Disponível em: <http://www.europarl.europa.eu/RegData/etudes/STUD/2016/587321/ IPOL_STU(2016)587321_EN.pdf>. Acesso em: 29 mar. 2017.

FERREIRA, Roberto; MACHADO, Costa; FERRAZ, Anna Candida da Cunha. Constituição Federal interpretada. 3. ed. São Paulo: Manole, 2012.

FUNDAÇÃO GETÚLIO VARGAS. Direito econômico regulatório. Rio de Janeiro: FGV, 2008.

GATTO, Ana Carolina dos Santos; OLIVEIRA, Amanda Flávio de. Direito econômico: evolução e institutos. Rio de Janeiro: Forense, 2009.

GOVERNO cobra 1,2 bilhão de euros de Roche e Novartis. Agência Italiana de Notícias, Roma, maio 2014. Disponível em: <http://ansabrasil.com.br/brasil/noticias/italia/ noticias/2014/05/28/Governo-cobra-1-2-bilhao-euros-Roche-Novartis_7806134.html>. Acesso em: 25 out. 2015.

HEY, Raul. Patentes e comércio internacional. Bussiness Review, 12 jun. 2013. Disponível em: $<\mathrm{http}$ ://www.dannemann.com.br/dsbim/Biblioteca_Detalhe.aspx? \&ID=861\&pp=1\&pi=2> Acesso em: 07 nov. 2015.

NISHIOKA, Sérgio de Andrade. Como é feito o registro de medicamentos novos no Brasil. Disponível em: <http://www.anvisa.gov.br/medicamentos/registro/artigo_pratica_ hospitalar.pdf $>$.

NOVARTIS e Roche condenadas por conluio. Setor Saúde, 10 mar. 2014. Disponível em: <http://setorsaude.com.br/novartis-e-roche-condenadas-por-conluio/>. Acesso em: 25 out. 2015 .

NOVARTIS e Roche multadas em Itália por concorrência desleal. Associação sem fins lucrativos para a defesa do consumidor, maio 2014. Disponível em: <http://www.deco.proteste.pt/saude/ medicamentos/noticia/novartis-e-roche-multadas-em-italia-por-concorrencia-desleal\# $>$. Acesso em: 25 out. 2015.

NOVARTIS. Lucentis. Disponível em: <https://portal.novartis.com.br/upload/ imgconteudos/1511.pdf $>$. Acesso em: 09 nov. 2015.

ORGANIZACIÓN MUNDIAL DEL COMERCIO - OMC. ORGANIZACIÓN MUNDIAL DE LA SALUD - OMS. Los acuerdos de La OMC y lasalud pública. OMC, 2002. Disponível em: <https://www.wto.org/spanish/res_s/booksp_s/who_wto_s.pdf >. Acesso em 05 jul. 2015.

PAMMOLLI, F; SALERNO, N. C. Distribuzione dei farmaci, tutela della salute e diritti soggettivi. Roma: CERM, 2006. 
PETERSEN, Letícia Lassen. Políticas sociais no SUS e a gestão da assistência farmacêutica na rede local/regional: o caso da judicialização na $17^{\text {a }}$ Coordenadoria Regional de Saúde - RS. 2014. Tese (Doutorado em Direito), Faculdade de Direito, Universidade de Santa Cruz do Sul, 2014. Disponível em: <http://btd.unisc.br/Teses/LeticiaPetersen.pdf>. Acesso em: 29 mar. 2017.

SALES, Fernando Augusto de Vita Borges de. A responsabilidade penal da pessoa jurídica por infração à ordem econômica. Portal de e-governo, inclusão digital e sociedade do conhecimento, 09 maio 2012. Disponível em: <http://www.egov.ufsc.br/portal/conteudo/responsabilidadepenal-da-pessoa-jur\%C3\%ADdica-por-infra\%C3\%A7\%C3\%A3o-\%C3\%A0-ordemecon $\% \mathrm{C} 3 \% \mathrm{~B} 4$ mica> .

SARLET, Ingo Wolfgang. A eficácia dos direitos fundamentais. 12. ed. Porto Alegre: Livr. do Advogado, 2015.

Dignidade da pessoa humana e direitos fundamentas na Constituição Federal de 1988. 9. ed. Porto Alegre: Livr. do Advogado, 2012.

SILVA, Francisco Viegas Neves da. Os Tratados de Livre Comércio e o Acordo TRIPS: uma análise da proteção patentária na área farmacêutica. 2009. Dissertação (Mestrado em Direito), Centro de Ciências Jurídicas, Universidade Federal de Santa Catarina, Florianópolis, 2009. Disponível em: <https://repositorio.ufsc.br/bitstream/handle/123456789/92504/267855. pdf? sequence $=1$ \&isAllowed $=y>$ Acesso em: 14 nov. 2015.

SQUIZZATO, Ana Carolina. Direito financeiro e econômico. São Paulo: Método, 2013.

Cristianne Maria Famer Rocha - Pós-Doutora pela Organização Pan-Americana de Saúde e Universidad Nacional de Educación a Distancia; doutora em Educação pela Universidade Federal do Rio Grande do Sul (UFRGS); mestre em Educação pela UFRGS. Professora adjunta do Programa de Pós-Graduação em Saúde Coletiva da UFRGS; professora colaboradora do Programa de PósGraduação em Saúde da Criança e Adolescente da UFRGS. Porto Alegre/RS, Brasil.

Letícia Lassen Petersen - Pós-Doutoranda no Programa de Pós-Graduação de Saúde Coletiva pela Universidade Federal do Rio Grande do Sul (UFRGS); doutora em Desenvolvimento Regional pela Universidade de Santa Cruz do Sul (Unisc); mestre em Desenvolvimento Regional pela Unisc; especialista em Novo Direito Civil pela Universidade do Sul de Santa Catarina; graduada em Ciências Jurídicas e Sociais pela Universidade Regional do Noroeste do Estado do Rio Grande do Sul (Unijuí), graduada em Pedagogia pela Unijuí. Analista jurídica da Procuradoria do Estado do Rio Grande do Sul. Porto Alegre/RS, Brasil. E-mail: letipetersen@yahoo.com.br.

Lígia Daiane Fink dos Santos - Mestranda do Programa de Pós-Graduação Stricto Sensu em Direito da Universidade Regional Integrada do Alto Uruguai e das Missões (Santo Ângelo); pós-graduanda em Direito Previdenciário e do Trabalho pelo Instituto Cenecista de Ensino Superior de Santo Ângelo; especialista em Direito Econômico, Penal e Tributário pela Faculdade de Educação e Tecnologia da Região Missioneira (São Paulo das Missões/ RS); graduada em Direito pela Fundação Educacional Machado de Assis. Porto Alegre/RS, Brasil.E-mail: ligia_daia@hotmail.com. 